\title{
KEMANFAATAN PERPUSTAKAAN DALAM PEMBELAJARAN DAN PENELITIAN MAHASISWA IPB SERTA STRATEGI PENINGKATANNYA
}

\author{
Janti Gristinawati Sujana ${ }^{1}$, Deden Himawan ${ }^{2}$ \\ 1,2Perpustakaan Institut Pertanian Bogor \\ jantigs@gmail.com,dedenhimawan63@gmail.com
}

\begin{abstract}
ABSTRAK
Pendahuluan. Menghadapi era disruptif Perpustakaan IPB perlu mengantisipasi berbagai perubahan dengan melakukan evaluasi diri melalui pengkajian manfaat keberadaannya bagi mahasiswa.
\end{abstract}

Tujuan. Penelitian ini bertujuan: (1) Mengetahui hubungan antara frekuensi kunjungan mahasiswa ke Perpustakaan IPB dengan IPK; (2) Mengetahui hubungan banyaknya buku Perpustakaan IPB yang dipinjam mahasiswa dengan IPK; (3) Mengetahui manfaat Perpustakaan IPB dalam mendukung proses pembelajaran dan penelitian mahasiswa; (4) Mengetahui peran pustakawan IPB dalam mendukung proses pembelajaran dan penelitian mahasiswanya; (5) Merumuskan strategi Perpustakaan IPB untuk meningkatkan manfaatnya terhadap proses pembelajaran dan penelitian mahasiswanya.

Metode. Penelitian ini merupakan penelitian kuantitatif, menggunakan uji korelasi untuk melihat hubungan antara frekuensi kunjungan mahasiswa ke Perpustakaan IPB dan banyaknya buku Perpustakaan IPB yang dipinjam mahasiswa dengan IPK. Penelitian ini juga menggunakan metode survei dengan kuesioner disertai wawancara kepada tiga orang dosen IPB.

Hasil. Hasil penelitian menunjukkan tidak ada korelasi antara frekuensi kunjungan mahasiswa ke perpustakaan dan banyaknya buku perpustakaan yang dipinjam dengan IPK mahasiswa. Namun demikian, persepsi mahasiswa terkait dukungan Perpustakaan IPB pada pembelajaran dan penelitian mereka sangat baik, rata-rata persentase responden yang setuju akan kemanfaatan perpustakaan dalam proses belajar dan penelitian mereka di atas $90 \%$. Persepsi responden terhadap dukungan pustakawan dalam membantu mahasiswa belajar sangat baik, namun untuk dukungan pustakawan pada penelitian mahasiswa dianggap kurang. Strategi peningkatan manfaat perpustakaan pada proses pembelajaran dan penelitian mahasiswa perlu disesuaikan dengan perilaku generasi milenial. Oleh karena itu disarankan Perpustakaan IPB segera mengimplementasikan konsep-konsep berbasiskan revolusi industri 4.0. Pustakawan IPB perlu ditingkatkan kompetensinya terkait keterampilan literasi informasi dan penguasaan pada teknologi informasi dan komunikasi.

Kata kunci: literasi informasi; pembelajaran mahasiswa; penelitian mahasiswa; revolusi industri 4.0; pustakawan IPB

\begin{abstract}
Introduction. Facing the disruptive era IPB Library needs to anticipate various changes by conducting selfevaluation through assessing the impact of their existence for students.

Objectives. This study aims: (1) Knowing the relationship between the frequency of student visits to the IPB Library and the GPA; (2) Knowing the relationship between the number of IPB library books borrowed by students and the GPA; (3) Knowing the benefits of the IPB Library in supporting student learning and research processes; (4) Knowing the role of IPB librarians in supporting the learning and research processes of their students; (5) Formulate strategies for the IPB Library to increase its benefits for the learning and research processes of its students.
\end{abstract}

Methods. This research is a quantitative study, using a correlation test to see the relationship between the frequency of student visits to the IPB Library and the number of the IPB Library books borrowed by the students with the GPA. This study also used a survey method with a questionnaire accompanied by interviews with three IPB lecturers. 


\begin{abstract}
Results. The results showed that there was no correlation between the frequency of student visits to the library and the number of library books borrowed on the student's GPA. However, students' perceptions regarding the support of the IPB Library on their learning and research are very good, the average percentage of respondents who agree on the benefits of the library in their learning and research processes is above $90 \%$. Respondents' perception of librarian support in helping students learn is very good, but librarian support for student research is considered lacking. Strategies to increase the benefits of the library and librarians on student learning and research process need to be adjusted to the behavior of the millennial generation. Therefore, it is recommended that the IPB Library immediately implement the concepts based on industrial revolution 4.0. IPB librarians should be improved their competence related to information literacy skills and mastery of information and communication technology.
\end{abstract}

Keywords: IPB librarians; IPB Library; industrial revolution 4.0; information literacy; students learning; students research

\section{PENDAHULUAN}

Dengan terjadinya perubahan teknologi informasi dan komunikasi yang luar biasa, akhir-akhir ini kehidupan manusia mengalami disrupsi. Banyak peristiwa terjadi yang mengagetkan masyarakat. Perusahaan raksasa dalam fotografi bernama Kodak yang dulu papan namanya dapat dibaca di manamana, sekarang ini sudah ditutup. Perusahaan Kodak merupakan salah satu korban perkembangan teknologi informasi. Begitu lahir kamera digital, orang tidak perlu lagi membeli film, tidak perlu lagi mencuci film yang kadangkadang merogoh kocek yang lumayan besar. Diramalkan masih banyak pekerjaan yang akan hilang akibat perkembangan teknologi informasi dan komunikasi yang luar biasa. Semua itu hilang karena tidak sesuai lagi dengan preferensi kehidupan zaman now, terutama dari generasi milenial.

Perpustakaan perguruan tinggi menghadapi pengguna yang semuanya generasi milenial terutama untuk Program Sarjana. Perpustakaan dan pustakawan harus waspada menghadapi perubahan zaman yang luar biasa, jangan terlena di zona nyaman, seolah-olah mahasiswa pasti membutuhkan perpustakaan. Hasil penelitian Sujana dkk. (2018) menunjukkan bahwa langkah pertama kebanyakan mahasiswa Institut Pertanian Bogor (IPB) dari generasi milenial dalam mencari informasi adalah melalui mesin pencari. Beberapa tahun terakhir peminjaman buku di Perpustakaan IPB terus menurun. Nzivo \& Chuanfu (2013) menyebarkan kuesioner kepada mahasiswa internasional dari Wuhan University di China. Hasil kajian ini menunjukkan bahwa 53.9\% mahasiswa internasional adakalanya membutuhkan bantuan, namun teman menjadi sumber bantuan yang terkemuka. Mahasiswa internasional program doktor kebanyakan menghubungi teman, ilmuwan senior dan mahasiswa program sarjana lebih suka menghubungi teman sekelas dan teman-teman orang China, hanya mahasiswa program master yang menghubungi pustakawan referensi.

Penelitian tentang manfaat atau dampak perpustakaan bagi penggunanya, terutama di perpustakaan perguruan tinggi, telah banyak dilakukan menggunakan berbagai metode dan beragam data yang dikumpulkan. Hasil-hasil penelitian tersebut sebagian menunjukkan nada pesimis pada dunia kepustakawanan, tetapi cukup banyak juga yang menunjukkan kebutuhan pengguna terhadap perpustakaan. Salah satu penelitian dari Jamaluddin (2014) di Universitas Hasanuddin menunjukkan terdapat hubungan antara intensitas pemanfaatan perpustakaan dengan prestasi belajar mahasiswa. Hasil analisis terhadap frekuensi pemanfaatan berbagai layanan memberi pengaruh positif yang signifikan pada nilai prestasi belajar mahasiswa. Selain itu Datig (2014) yang mengkaji persepsi mahasiswa internasional terhadap Perpustakaan New York University Abu 
Dhabi, United Arab Emirates memaparkan seorang mahasiswa universitas tersebut berpendapat "Perpustakaan sangat penting untuk memperkuat pengetahuan yang diperoleh mahasiswa di kelas dan juga untuk menyediakan tempat yang tenang dan nyaman untuk belajar." Ohoiwutun dkk. (2014) melakukan penelitian untuk melihat dampak dari manajemen koleksi perpustakaan terhadap minat baca mahasiswa Jurusan Ilmu Keperawatan Universitas Katolik De La Salle Manado. Hasil penelitian menunjukkan koefisien korelasi kedua variabel itu adalah 0.988 , artinya hubungan antara kedua variabel itu sangat kuat. Manajemen koleksi perpustakan dapat memberikan sumbangan/kontribusi terhadap minat baca mahasiswa Jurusan Ilmu Keperawatan Universitas Katolik De La Salle Manado.

Pola pemanfaatan perpustakaan telah berubah karena preferensi generasi telah berubah. Perpustakaan IPB harus mengukur kemanfaatannya terhadap pembelajaran dan penelitian bagi sivitas akademika IPB, terutama mahasiswa generasi milenial, agar tidak ditinggalkan oleh penggunanya. Selain itu perlu dirancang strategi peningkatan kemanfaatan Perpustakaan IPB pada kegiatan pembelajaran dan penelitian mahasiswa IPB, agar Perpustakaan IPB dapat tetap menjadi penunjang pelaksanaan pembelajaran dan penelitian yang dapat diandalkan oleh mahasiswa IPB.

Berdasarkan situasi dan kondisi yang terjadi di era disrupsi, maka Perpustakaan IPB perlu evaluasi diri melalui kajian, sehingga tujuan penelitian ini adalah: 1) Mengetahui hubungan antara frekuensi kunjungan mahasiswa ke Perpustakaan IPB dengan Indeks Prestasi Kumulatif (IPK); 2) Mengetahui hubungan banyaknya buku Perpustakaan IPB yang dipinjam mahasiswa dengan IPK; 3) Mengetahui manfaat Perpustakaan IPB dalam mendukung proses pembelajaran dan penelitian mahasiswa; 4) Mengetahui peran pustakawan IPB dalam mendukung proses pembelajaran dan penelitian mahasiswanya; 5) Merumuskan strategi Perpustakaan IPB untuk meningkatkan manfaatnya terhadap proses pembelajaran dan penelitian mahasiswanya.

Penelitian ini dilaksanakan SeptemberDesember 2019, dibatasi pada pengguna dari mahasiswa Program Sarjana IPB di Kampus IPB Darmaga, Bogor. Pertimbangannya mahasiswa Program Sarjana adalah mayoritas mahasiswa di IPB, dan mereka semua berasal dari generasi milenial. Kajian ini menggunakan kata pustakawan untuk mewakili semua staf/pegawai yang bekerja di Perpustakaan IPB, baik tenaga administrasi perpustakaan, maupun tenaga terampil perpustakaan dan tenaga ahli perpustakaan yang menyandang jabatan fungsional pustakawan, yang mendukung terlaksananya layanan perpustakaan.

\section{Metode Penelitian}

Penelitian ini merupakan penelitian kuantitatif, menggunakan uji korelasi Pearson atau Product Moment Correlation untuk melihat hubungan antara frekuensi kunjungan mahasiswa ke Perpustakaan IPB dan banyaknya buku Perpustakaan IPB yang dipinjam mahasiswa dengan Indeks Prestasi Kumulatif (IPK). Penelitian ini juga menggunakan metode survei dengan kuesioner sebagai instrumen pengumpulan data untuk melihat manfaat perpustakaan dan peran pustakawan terhadap proses pembelajaran dan penelitian mahasiswa, serta strategi meningkatkan manfaat perpustakaan.

Untuk menghitung korelasi Pearson rumusnya sebagai berikut.

$$
\begin{aligned}
& r= \frac{\sum_{i=1}^{n} x_{i} y_{i}}{\sqrt{\sum_{i=}^{n} x_{i}^{2}}} \sqrt{\sum_{i=}^{n} y_{i}^{2}} \\
& \mathrm{x}_{\mathrm{i}}=\mathrm{X}_{\mathrm{i}}-\overline{\mathrm{X}} ; \text { dan } \mathrm{y}_{\mathrm{i}}=\mathrm{Y}_{\mathrm{i}}-\mathrm{Y} \\
& \mathrm{n}=\text { jumlah data }
\end{aligned}
$$

Sumber: Supranto, J. (2016) 
Untuk mengetahui signifikansi hubungan antara dua variabel dilakukan uji korelasi, melalui penghitungan nilai t untuk sampel kecil. Rumus nilai $\mathrm{t}$ untuk korelasi Spearman adalah sebagai berikut.

$$
t=r \sqrt{\frac{n-2}{1-r^{2}}}
$$

Sumber: Irianto, A. (2008)

Untuk menentukan kekuatan hubungan antara dua variabel, Tabel 1 mendeskripsikan arti nilai koefisien korelasi (r).

Tabel 1. Interval koefisien korelasi nilai $\mathrm{r}$

\begin{tabular}{cl}
\hline $\begin{array}{c}\text { Interval } \\
\text { koefisien }\end{array}$ & \multicolumn{1}{c}{$\begin{array}{c}\text { Tingkat } \\
\text { hubungan }\end{array}$} \\
\hline $0.00-0.199$ & Sangat rendah \\
$0.20-0.399$ & Rendah \\
$0.40-0.599$ & Cukup \\
$0.60-0.799$ & Kuat \\
$0.80-1.000$ & Sangat kuat \\
\hline Sumber: Riduwan (2009)
\end{tabular}

Kajian hubungan antara frekuensi kunjungan ke perpustakaan dengan IPK melalui pengukuran koefisien korelasi dan uji korelasi mengambil sampel secara purposive random sampling 100 mahasiswa semester 4 - 5 pada tahun 2017 dan semester $6-7$ pada tahun 2018, diawali dengan frekuensi kunjungan ke perpustakaan tertinggi pada tahun 2018 . Kemudian untuk mengukur hubungan antara banyaknya buku perpustakaan yang dipinjam dengan IPK, dilakukan pengambilan sampel secara purposive random sampling. Untuk itu dipilih 100 mahasiswa dari semester 4 - 5 pada tahun 2017 dan semester $6-7$ pada tahun 2018, diawali dengan pengambilan data peminjam buku terbanyak pada tahun 2018. Nama-nama yang sama diminta data Indeks Prestasi Kumulatif (IPK) kepada Direktorat Administrasi Pendidikan dan Penerimaan Mahasiswa Baru IPB untuk semester genap 2016/2017, semester ganjil dan genap
2017/2018, dan semester ganjil 2018/ 2019. Semua data itu menjadi bahan penghitungan koefisien korelasi Pearson dan diuji korelasi untuk melihat adakah hubungan dan kekuatan hubungan antara frekuensi kunjungan ke perpustakaan dan banyaknya buku perpustakaan yang dipinjam mahasiswa dengan pembelajaran yang diukur melalui Indeks Prestasi Kumulatif.

Pada pengumpulan data melalui survei, kuesioner sebelum disebarkan kepada responden dilakukan uji coba kepada 30 orang mahasiswa. Hasil uji coba kuesioner diuji validitasnya menggunakan rumus korelasi product moment dan reliabilitasnya menggunakan Cronbach' Alpha. Setelah kuesioner diperbaiki, disebarkan kepada mahasiswa yang terpilih sebagai responden. Sampel responden dipilih secara purposive random sampling dengan target 200 responden, karena responden haruslah mahasiswa yang sedang atau telah melakukan penelitian. Data yang diperoleh dari kuesioner diolah menggunakan software Statistical Package for Social Sciences (SPSS) dan ditampilkan dalam tabulasi. Untuk lebih memperluas dan memperdalam rekomendasi strategi peningkatan manfaat perpustakaan dilakukan wawancara kepada tiga orang dosen IPB.

\section{Hasil dan Pembahasan}

Pembahasan hasil kajian yang pertama terkait hasil pengolahan data terhadap data kunjungan mahasiswa ke perpustakaan dan data peminjaman buku dihubungkan dengan prestasi belajar mahasiswa.

\section{Hasil uji korelasi}

Sesuai dengan metode penelitian yang telah dirumuskan, untuk melihat hubungan kunjungan mahasiswa ke perpustakaan dan buku yang dipinjam dengan prestasi belajar mahasiswa, digunakan uji korelasi. Hasil uji korelasi yang dilakukan pada penelitian ini 
menunjukkan tidak ada korelasi antara frekuensi kunjungan mahasiswa ke perpustakaan dengan IPK seperti ditunjukkan oleh Tabel 2. Begitu juga tidak ada korelasi antara banyaknya buku perpustakaan yang dipinjam dengan IPK mahasiswa seperti ditunjukkan oleh Tabel 3. Hasil penelitian ini berbeda dari hasil penelitian Jamaluddin (2014) di Universitas Hasanuddin. Hasil penelitian itu menunjukkan terdapat hubungan antara intensitas pemanfaatan perpustakaan dengan prestasi belajar mahasiswa dengan koefisien korelasi sebesar 0.653. Hasil analisis Jamaluddin terhadap frekuensi pemanfaatan berbagai layanan memberi pengaruh positif yang signifikan pada nilai prestasi belajar mahasiswa. Namun demikian, hasil penelitian Daruyani dkk. (2013) terhadap mahasiswa Fakultas Sains dan Matematika semester pertama Universitas Diponegoro menunjukkan bahwa banyak variabel mempengaruhi indeks prestasi mahasiswa, yaitu nilai rapor dan nilai ujian nasional semasa di Sekolah Menengah Atas, jalur masuk ke perguruan tinggi, pilihan jurusan, tempat tinggal, metode belajar, biaya hidup per bulan, hubungan mahasiswa dengan keluarga dan teman, serta motivasi belajar. Dengan demikian dapat disimpulkan bahwa mahasiswa yang rajin memanfaatkan pepustakaan atau yang banyak meminjam buku perpustakaan tidak selalu mengakibatkan indeks prestasinya tinggi, karena banyak variabel lain yang mempengaruhi. Hal itu sesuai dengan hasil kajian ini bahwa mahasiswa yang sering datang ke Perpustakaan IPB dan banyak meminjam buku perpustakaan tidak berkorelasi dengan IPK yang dicapainya, karena banyak variabel lain yang mempengaruhi pencapaian IPK.

Tabel 2. Hasil analisis korelasi antara frekuensi kunjungan ke perpustakaan dan IPK

\begin{tabular}{|c|c|c|c|c|c|c|}
\hline & & & $\begin{array}{c}\text { IPK } \\
\text { 2016/2017 } \\
\text { Sem. Genap }\end{array}$ & $\begin{array}{c}\text { IPK } \\
2017 / 2018 \\
\text { Sem. Ganjil } \\
\end{array}$ & $\begin{array}{c}\text { IPK } \\
\text { 2017/2018 } \\
\text { Sem. Genap } \\
\end{array}$ & $\begin{array}{c}\text { IPK } \\
\text { 2018/2019 } \\
\text { Sem. Ganjil } \\
\end{array}$ \\
\hline \multirow[t]{6}{*}{$\begin{array}{c}\text { Spearman's } \\
\text { rho }\end{array}$} & \multirow{3}{*}{$\begin{array}{c}\text { Frekuensi } \\
\text { kunjungan thn } \\
2017\end{array}$} & $\begin{array}{l}\text { Correlation } \\
\text { Coefficient }\end{array}$ & 0.018 & 0.005 & -0.009 & 0.007 \\
\hline & & $\mathrm{p}$-value & 0.857 & 0.958 & 0.927 & 0.944 \\
\hline & & $\mathrm{N}$ & 100 & 100 & 100 & 100 \\
\hline & \multirow{3}{*}{$\begin{array}{c}\text { Frekuensi } \\
\text { kunjungan thn } \\
2018\end{array}$} & $\begin{array}{l}\text { Correlation } \\
\text { Coefficient }\end{array}$ & 0.153 & 0.133 & 0.126 & 0.123 \\
\hline & & $\mathrm{p}$-value & 0.128 & 0.188 & 0.210 & 0.224 \\
\hline & & $\mathrm{N}$ & 100 & 100 & 100 & 100 \\
\hline
\end{tabular}

Tabel 3. Analisis korelasi antara jumlah buku perpustakaan yang dipinjam dengan IPK

\begin{tabular}{|c|c|c|c|c|c|c|}
\hline & & & $\begin{array}{c}\text { IPK } \\
\text { 2016/2017 } \\
\text { Sem. Genap }\end{array}$ & $\begin{array}{c}\text { IPK } \\
2017 / 2018 \\
\text { Sem. Ganjil }\end{array}$ & $\begin{array}{c}\text { IPK } \\
2017 / 2018 \\
\text { Sem. Genap }\end{array}$ & $\begin{array}{c}\text { IPK } \\
\text { 2018/2019 } \\
\text { Sem. Ganjil }\end{array}$ \\
\hline \multirow[t]{6}{*}{$\begin{array}{c}\text { Spearman's } \\
\text { rho }\end{array}$} & \multirow{3}{*}{$\begin{array}{l}\text { Jumlah buku } \\
\text { dipinjam thn } \\
2017\end{array}$} & $\begin{array}{l}\text { Correlation } \\
\text { Coefficient }\end{array}$ & -0.051 & -0.045 & -0.047 & -0.059 \\
\hline & & Sig. (2-tailed) & 0.616 & 0.658 & 0.643 & 0.563 \\
\hline & & $\mathrm{N}$ & 100 & 100 & 100 & 100 \\
\hline & \multirow{3}{*}{$\begin{array}{c}\text { Jumlah buku } \\
\text { dipinjam thn } \\
2018\end{array}$} & $\begin{array}{l}\text { Correlation } \\
\text { Coefficient }\end{array}$ & 0.037 & 0.021 & 0.007 & 0.000 \\
\hline & & Sig. (2-tailed) & 0.712 & 0.836 & 0.941 & 1.000 \\
\hline & & $\mathrm{N}$ & 100 & 100 & 100 & 100 \\
\hline
\end{tabular}

\section{Hasil Penyebaran Kuesioner}

Selanjutnya dibahas hasil penyebaran kuesioner kepada responden yang ditargetkan 200 mahasiswa, namun kuesioner yang terkumpul ada 205 set. Data dikelompokkan berdasarkan unsur- 
unsur yang berhubungan dengan perpustakaan atau pustakawan, kemudian kaitannya dengan pembelajaran atau penelitian. a. Manfaat Perpustakaan pada Proses Pembelajaran

Tabel 4. Persepsi Responden tentang Dampak Perpustakaan pada Pembelajaran

\begin{tabular}{|c|l|r|r|}
\hline No. & \multicolumn{1}{|c|}{ Uraian } & \multicolumn{1}{|c|}{$\begin{array}{c}\text { Setuju dan } \\
\text { Sangat } \\
\text { Setuju (\%) }\end{array}$} & $\begin{array}{c}\text { Tidak Setuju } \\
\text { dan Sangat } \\
\text { Tidak Setuju } \\
\text { (\%) }\end{array}$ \\
\hline 1 & $\begin{array}{l}\text { Koleksi buku tercetak Perpustakaan bermanfaat } \\
\text { terhadap pembelajaran }\end{array}$ & 96,6 & 3,4 \\
\hline 2 & $\begin{array}{l}\text { Koleksi buku elektronik Perpustakaan } \\
\text { bermanfaat untuk pembelajaran }\end{array}$ & 95,1 & 4,9 \\
\hline 3 & $\begin{array}{l}\text { Koleksi jurnal tercetak Perpustakaan bermanfaat } \\
\text { untuk pembelajaran }\end{array}$ & 92,2 & 7,8 \\
\hline 4 & $\begin{array}{l}\text { Koleksi jurnal elektronik Perpustakaan } \\
\text { bermanfaat untuk pembelajaran }\end{array}$ & 9,0 \\
\hline 5 & $\begin{array}{l}\text { Fasilitas komputer di perpustakaan membantu } \\
\text { proses pembelajaran }\end{array}$ & 9,0 \\
\hline 6 & $\begin{array}{l}\text { Fasilitas komputer dan jaringan internet di } \\
\text { Perpustakaan membantu responden mencari } \\
\text { informasi untuk tugas-tugas kuliah }\end{array}$ & 96,6 & 3,4 \\
\hline 7 & $\begin{array}{l}\text { Wi-fi di Perpustakaan membantu pencarian } \\
\text { informasi untuk tugas-tugas kuliah }\end{array}$ & 9,6 \\
\hline 8 & $\begin{array}{l}\text { Kenyamanan ruangan membuat mahasiswa } \\
\text { senang belajar di Perpustakaan }\end{array}$ & $\begin{array}{l}\text { Mahasiswa merasa aman bila belajar di } \\
\text { Perpustakaan }\end{array}$ & $9,9,2$ \\
\hline 10 & $\begin{array}{l}\text { Di Perpustakaan dapat belajar bersama teman, } \\
\text { sehingga lebih bersemangat }\end{array}$ & 9,4 \\
\hline
\end{tabular}

Unsur pertama dengan persentase tertinggi dari hasil penyebaran kuesioner yang menyatakan setuju dan sangat setuju berada pada persepsi responden terhadap "koleksi jurnal elektronik Perpustakaan bermanfaat untuk pembelajaran" dengan angka 98,0\%. Angka persentase tertinggi kedua ada pada dua persepsi tentang "koleksi buku tercetak Perpustakaan bermanfaat terhadap pembelajaran" dan "fasilitas komputer dan jaringan internet di Perpustakaan membantu mahasiswa mencari informasi untuk tugas-tugas kuliah" dengan masing-masing 96,6 \%. Angka persentase tertinggi ketiga juga ada pada dua persepsi mahasiswa tentang "fasilitas komputer di Perpustakaan membantu proses pembelajaran" dan "kenyamanan ruangan membuat mahasiswa senang belajar di
Perpustakaan" dengan masing-masing 95,6 \%. Pilihan terhadap berbagai pernyataan di kuesioner yang memperoleh persentase tertinggi sesuai dengan perilaku generasi milenial yang telah banyak dibicarakan dalam berbagai kesempatan. Generasi milenial tidak bisa lepas dari komputer, jaringan internet dan materi digital. Kenyamanan ruangan ditengarai juga merupakan salah satu kesenangan generasi milenial, bahkan akan menjadi tempat yang lebih disukai lagi bila dilengkapi dengan cafe. Pilihan pada koleksi buku tercetak masih ada, mungkin disebabkan oleh koleksi buku elektronik Perpustakaan IPB belum banyak, sehingga mereka terpaksa tetap menggunakan buku tercetak.

b. Manfaat Perpustakaan pada Proses Penelitian 


\begin{tabular}{|c|c|c|c|}
\hline No. & Uraian & $\begin{array}{l}\text { Setuju dan } \\
\text { Sangat } \\
\text { Setuju }(\%)\end{array}$ & $\begin{array}{l}\text { Tidak Setuju } \\
\text { dan Sangat } \\
\text { Tidak Setuju } \\
(\%)\end{array}$ \\
\hline 1 & $\begin{array}{l}\text { Koleksi buku tercetak Pepustakaan bermanfaat } \\
\text { untuk penelitian mahasiswa }\end{array}$ & 93,7 & 6,4 \\
\hline 2 & $\begin{array}{l}\text { Koleksi buku elektronik Perpustakaan bermanfaat } \\
\text { untuk penelitian mahasiswa }\end{array}$ & 94,1 & 5,9 \\
\hline 3 & $\begin{array}{l}\text { Koleksi jurnal tercetak Perpustakaan bermanfaat } \\
\text { untuk penelitian mahasiswa }\end{array}$ & 90,3 & 9,8 \\
\hline 4 & $\begin{array}{l}\text { Koleksi jurnal elektronik Perpustakaan bermanfaat } \\
\text { untuk penelitian mahasiswa }\end{array}$ & 97,6 & 2,5 \\
\hline 5 & $\begin{array}{l}\text { Koleksi skripsi tercetak Perpustakaan membantu } \\
\text { proses penelitian mahasiswa }\end{array}$ & 91,7 & 8,3 \\
\hline 6 & $\begin{array}{l}\text { Koleksi skripsi di repository IPB membantu proses } \\
\text { penelitian mahasiswa }\end{array}$ & 98,5 & 1,5 \\
\hline 7 & $\begin{array}{l}\text { Tersedianya komputer di Perpustakaan membantu } \\
\text { mahasiswa mengerjakan proses penelitiannya }\end{array}$ & 95,1 & 4,9 \\
\hline 8 & $\begin{array}{l}\text { Tersedianya komputer dan jaringan internet di } \\
\text { Perpustakaan membantu mahasiswa mencari } \\
\text { informasi untuk penelitiannya }\end{array}$ & 96,6 & 3,4 \\
\hline 9 & $\begin{array}{l}\text { Tersedianya wi-fi di Perpustakaan membantu } \\
\text { mahasiswa mencari informasi untuk penelitiannya }\end{array}$ & 93,6 & 6,3 \\
\hline 10 & $\begin{array}{l}\text { Ruangan Perpustakaan nyaman, membuat } \\
\text { mahasiswa dapat mengerjakan laporan penelitiannya }\end{array}$ & 96,6 & 3,4 \\
\hline 11 & $\begin{array}{l}\text { Mengerjakan laporan penelitian bersama teman di } \\
\text { Perpustakaan membuat mahasiswa lebih produktif }\end{array}$ & 91,7 & 8,3 \\
\hline 12 & $\begin{array}{l}\text { Layanan data penelitian di Perpustakaan dapat } \\
\text { mempercepat penelitian mahasiswa }\end{array}$ & 96,1 & 3,9 \\
\hline
\end{tabular}

Unsur dari Perpustakaan yang mendapat persentase tertinggi ada pada "koleksi skripsi di repository IPB membantu proses penelitian mahasiswa" sebesar 98,5\%. Koleksi skripsi dari masih format tercetak menjadi sumber informasi yang sangat digemari mahasiswa. Pustakawan yang bertugas di koleksi skripsi sering mengeluh banyaknya skripsi yang harus dirakkan kembali setelah digunakan mahasiswa. Pemanfaatan skripsi yang tinggi dapat dimaklumi karena mahasiswa yang mengerjakan tugas akhir merasa penting untuk merujuk pada apa yang telah dilakukan mahasiswa seniornya. Terlebih sekarang dalam format digital, lebih mudah dan cepat untuk mendapatkan skripsi yang relevan. Persentase tertinggi kedua ada pada "koleksi jurnal elektronik Perpustakaan bermanfaat untuk penelitian mahasiswa" dengan angka 97,6 $\%$. Persentase tertinggi ketiga ada pada persepsi mahasiswa pada dua pilihan yaitu “tersedianya komputer dan jaringan internet di Perpustakaan membantu mahasiswa mencari informasi untuk penelitian" dan "ruangan Perpustakaan nyaman membuat mahasiswa dapat mengerjakan laporan penelitiannya" masing-masing sebesar 96,6 \%. Pada pokok bahasan manfaat perpustakaan pada penelitian mahasiswa jelas semua pilihan yang memperoleh persentase tertinggi kembali sesuai dengan perilaku generasi milenial.

Hasil penelitian ini menunjukkan koleksi jurnal elektronik sangat dibutuhkan mahasiswa baik untuk pembelajaran maupun penelitian. Perpustakaan IPB perlu menjaga kesinambungan langganan pada jurnal elektronik. Hasil penelitian Montenegro dkk. (2016) menunjukkan bahwa akses terhadap sumber-sumber daya elektronik (seperti jurnal elektronik dan database online) mempunyai efek yang lebih besar pada nilai mahasiswa dari pada meminjam 
bahan perpustakaan tercetak (seperti buku, jurnal atau tesis tercetak). Fasilitas komputer dan jaringan internet di Perpustakaan sangat membantu mahasiswa dalam proses belajar dan penelitian. Oleh karena itu Perpustakaan IPB perlu terus menambah jumlah komputer, mengantisipasi masih banyaknya mahasiswa yang tidak mempunyai laptop mengingat mahasiswa IPB cukup banyak berasal dari keluarga yang sederhana. Bandwidth internet untuk Perpustakaan perlu diusahakan terus ditambah, banyak mahasiswa mengandalkan wi-fi yang disediakan Perpustakaan untuk berbagai keperluan akses informasi. Ruang Perpustakaan yang nyaman termasuk yang banyak dibutuhkan mahasiswa, baik untuk belajar maupun untuk menulis laporan penelitian. Ruang yang nyaman membuat orang dapat bertahan lama untuk terus bekerja, mencari inspirasi untuk menghasilkan inovasi. Menurut Li dkk. (2018) perpustakaan universitas masih mempertahankan peran yang tak tergantikan sebagai tempat pembelajaran bersama. Hasil peelitian Datig (2014) terhadap mahasiswa internasional di New York University Abu Dhabi, United Arab Emirates menunjukkan pentingnya perpustakaan sebagai tempat belajar dari pernyataan seorang mahasiswa yang diwawancara sebagai berikut:

"Dengan melihat banyak orang belajar atau dengan buku terbuka, itu membuat Anda berpikir bahwa Anda juga harus merasa itu adalah tempat untuk belajar ... Dan fakta bahwa ada banyak orang di sana, itu bukan faktor yang mengganggu karena sering kali orang bisa mendapatkan energi dari orang lain di sekitar mereka juga bekerja. "

c. Peran Pustakawan dalam Mendukung Proses Pembelajaran

\begin{tabular}{|c|l|r|r|}
\hline No. & \multicolumn{1}{|c|}{ Uraian } & \multicolumn{1}{|c|}{$\begin{array}{c}\text { Setuju dan } \\
\text { Sangat } \\
\text { Setuju (\%) }\end{array}$} & $\begin{array}{c}\text { Tidak Setuju } \\
\text { dan Sangat } \\
\text { Tidak Setuju } \\
\mathbf{( \% )}\end{array}$ \\
\hline 1 & $\begin{array}{l}\text { Pustakawan membantu mahasiswa dalam mencari } \\
\text { informasi untuk pembelajaran }\end{array}$ & 9,4 \\
\hline 2 & $\begin{array}{l}\text { Pustakawan membantu mahasiswa mencari buku yang } \\
\text { tidak ditemukan }\end{array}$ & 92,7 \\
\hline 3 & $\begin{array}{l}\text { Pustakawan mengajarkan mahasiswa cara mencari } \\
\text { informasi }\end{array}$ & 84,4 \\
\hline 4 & $\begin{array}{l}\text { Pustakawan selalu siap menjawab pertanyaan } \\
\text { mahasiswa }\end{array}$ & 96,1 \\
\hline 5 & $\begin{array}{l}\text { Pustakawan memberikan saran untuk sumber-sumber } \\
\text { informasi yang relevan dengan kebutuhan mahasiswa }\end{array}$ & 3,9 \\
\hline 6 & $\begin{array}{l}\text { Keramahan Pustakawan membuat mahasiswa } \\
\text { berlama-lama belajar di Perpustakaan }\end{array}$ & 81,4 \\
\hline 7 & $\begin{array}{l}\text { Pustakawan mempunyai cukup pengetahuan } \\
\text { menjawab pertanyaan mahasiswa }\end{array}$ & 90,2 \\
\hline
\end{tabular}

Pendapat responden tentang dukungan pustakawan bagi proses pembelajaran, persentase tertinggi pada pernyataan "pustakawan selalu siap menjawab pertanyaan mahasiswa" yaitu sebesar 96,1 \%. Angka persentase tertinggi kedua pada pernyataan "pustakawan membantu mahasiswa dalam mencari informasi untuk pembelajaran" sebesar 94,6\%. Angka persentase tertinggi ketiga ada pada persepsi mahasiswa terhadap "pustakawan membantu mahasiswa mencari buku yang tidak ditemukan" sebesar 92,7 $\%$. Ketiga peran pustakawan yang paling banyak dirasakan mahasiswa masih didominasi oleh peran pustakawan yang konvensional, padahal pustakawan perpustakaan perguruan tinggi masa kini seharusnya memberikan keterampilan 
literasi informasi kepada mahasiswa agar mereka siap menghadapi informasi yang berlimpah. d. Peran Pustakawan dalam Mendukung Proses Penelitia

\begin{tabular}{|c|l|r|r|}
\hline No. & \multicolumn{1}{|c|}{ Uraian } & \multicolumn{1}{|c|}{$\begin{array}{c}\text { Setuju dan } \\
\text { Sangat } \\
\text { Setuju (\%) }\end{array}$} & $\begin{array}{c}\text { Tidak Setuju dan } \\
\text { Sangat Tidak } \\
\text { Setuju (\%) }\end{array}$ \\
\hline 1 & $\begin{array}{l}\text { Pustakawan membantu mahasiswa mencari } \\
\text { informasi untuk penelitiannya }\end{array}$ & 15,1 \\
\hline 2 & $\begin{array}{l}\text { Pustakawan memberikan saran kepada mahasiswa } \\
\text { dalam mencari informasi yang relevan untuk } \\
\text { penelitiannya }\end{array}$ & 84,9 & 15,6 \\
\hline 3 & $\begin{array}{l}\text { Pustakawan membantu mahasiswa mengevaluasi } \\
\text { informasi untuk laporan penelitiannya }\end{array}$ & 78,0 & 22,0 \\
\hline 4 & $\begin{array}{l}\text { Pustakawan membantu mahasiswa menulis daftar } \\
\text { pustaka pada laporan penelitiannya }\end{array}$ & 63,9 & 19,0 \\
\hline 5 & $\begin{array}{l}\text { Pustakawan membantu mahasiswa menghindari } \\
\text { plagiarisme pada laporan penelitiannya }\end{array}$ & 81,0 & 19,0 \\
\hline
\end{tabular}

Selanjutnya hasil pengumpulan data terkait persepsi mahasiswa terhadap dukungan pustakawan dalam proses penelitian mahasiswa menunjukkan persentase tertinggi ada pada "pustakawan membantu mahasiswa mencari informasi untuk penelitian" sebesar 84,9 \%. Persentase tertinggi kedua ada pada "pustakawan memberikan saran kepada mahasiswa dalam mencari informasi yang relevan untuk penelitiannya" sebesar 84,4 $\%$. Angka persentase tertinggi ketiga ada pada "pustakawan membantu mahasiswa menghindari plagiarisme pada laporan penelitian" sebesar 81,0 \%. Pustakawan membantu mahasiswa mencari informasi untuk pembelajaran dan penelitian dirasakan banyak mahasiswa. Namun demikian bila diperhatikan angka-angka persentase yang diperoleh pada dukungan pustakawan pada proses penelitian mahasiswa, angka paling tinggi yang dicapai hanya 84,9 \%, sedangkan pada pokok bahasan lain kebanyakan di atas 90 $\%$. Dengan demikian perlu menjadi perhatian pustakawan IPB dalam memberikan dukungan pada proses penelitian mahasiswa di masa depan. Di era perpustakaan 4.0 ini sebenarnya pustakawan dituntut untuk mendukung mahasiswa bahkan sampai pendampingan untuk proses pembuatan proposal penelitian, pelaksanaan penelitian, membuat laporan hasil penelitian dan mempublikasikan hasil penelitiannya.

\section{Unsur-unsur dari Perpustakaan dan Pustakawan yang Dibutuhkan Mahasiswa}

Dalam rangka ingin mengetahui unsur-unsur layanan atau fasilitas yang dibutuhkan oleh mahasiswa dari Perpustakaan dan pustakawan IPB yang sangat bermanfaat dalam proses pembelajaran dan penelitian mereka, kuesioner pada kajian ini memberi daftar berbagai layanan atau fasilitas yang mungkin dibutuhkan mahasiswa, dan memberi kesempatan juga kepada responden menuliskan layanan atau fasilitas lain yang tidak ada pada daftar. Responden diminta untuk memilih tiga unsur yang sangat bermanfaat untuk kegiatan pembelajaran dan penelitian mereka.

Dari hasil pengolahan data terkait unsur pilihan dari Perpustakaan yang dirasa responden dapat membantu mahasiswa S1 dalam proses pembelajaran selama di IPB, tiga unsur yang dipilih responden paling banyak adalah 1) "Koleksi e-jurnal yang sesuai kurikulum", dipilih 50,73\% responden; 2) "Koleksi ebook yang sesuai dengan kurikulum" dan 
"bandwidth internet yang besar", samasama dipilih oleh 44,39\% responden; dan 3) "Ruang perpustakaan yang nyaman", dipilih oleh 39,02\% responden. Ketiga unsur yang paling banyak dipilih responden ini ternyata sama saja dengan pilihan yang memperoleh persentase tertinggi dari data yang disajikan pada manfaat Perpustakaan pada proses pembelajaran dan penelitian, kebutuhan generasi milenial.

Selanjutnya dipaparkan unsur Perpustakaan yang paling banyak dipilih responden yang dapat membantu proses penelitian mahasiswa S1. Adapun tiga unsur dari Perpustakaan yang dipilih paling banyak oleh responden untuk proses penelitian mahasiswa adalah 1) "Koleksi e-jurnal yang sesuai kurikulum", dipilih oleh 61,95 \% responden; 2) "Koleksi e-book yang sesuai dengan kurikulum", dipilih oleh 48,29 \% responden; dan 3) "Bandwidth internet yang besar", dipilih oleh 42,44 \% responden. Pilihan ini ternyata sama saja dengan unsur yang paling banyak dipilih responden untuk pembelajaran mahasiswa.

Pembahasan selanjutnya terkait unsur-unsur yang diinginkan mahasiswa terhadap pustakawan agar mereka dapat terbantu selama belajar di IPB. Tiga unsur yang paling tinggi diinginkan responden adalah 1) "Pustakawan mengajarkan strategi mencari informasi", dipilih oleh $84,39 \%$ responden; 2) "Pustakawan mempunyai pengetahuan yang cukup untuk menjawab pertanyaan mahasiswa", dipilih oleh 66,34\%; 3) "Pustakawan mengajarkan cara mengevaluasi informasi", dipilih oleh 60,98 \% responden.

Berikut ini pendataan keinginan responden terhadap pustakawan agar mahasiswa dibantu ketika proses penelitian. Tiga unsur yang paling banyak diinginkan oleh responden adalah 1) "Pustakawan mengajarkan strategi mencari informasi", dipilih oleh 63,90\% responden; 2) "Pustakawan mengajarkan pengecekan plagiarisme", dipilih oleh 58,54 \% responden; dan 3) "Pustakawan mengajarkan cara membuat kutipan dari sumber informasi”, dipilih oleh 44,39\% responden.

Identifikasi kebutuhan mahasiswa terhadap bantuan dari pustakawan untuk proses pembelajaran dan penelitian menunjukkan kebutuhan akan keterampilan literasi informasi. Hasil penelitian Rinto \& Cogbill-Seiders (2015) menunjukkan bahwa pelatihan literasi informasi memberikan dampak yang mendalam terhadap pembelajaran mahasiswa. Banyak hasil penelitian juga menunjukkan bahwa keterampilan literasi informasi sangat membantu mahasiswa dalam melaksanakan penelitian. Hasil penelitian ini menunjukkan bahwa perpustakaan berperan penting dalam proses pembelajaran dan penelitian mahasiswa. Namun demikian, perpustakaan dan pustakawan harus bertransformasi menyesuaikan pada kebutuhan pengguna masa kini, terutama pengguna dari generasi milenial. Perpustakaan di perguruan tinggi harus lebih melekat pada kegiatan pembelajaran dan penelitian sivitas akademikanya, tidak hanya sekedar mendiseminasikan informasi kepada penggunanya. Perpustakaan tidak dapat bertahan dengan prinsip-prinsip yang kaku di masa lalu.

\section{Strategi Peningkatan Dampak Positif Dalam rangka membuat} Perpustakaan IPB semakin jelas melangkah ke depan menghadapi era disrupsi, Perpustakaan IPB harus mempunyai strategi agar manfaat dari keberadaan perpustakaan dirasakan positif oleh mahasiswa. Untuk melengkapi dan meluaskan wawasan penulis dalam menyusun strategi, kajian ini mewawancara tiga orang dosen IPB yang selanjutnya akan disebut sebagai Narasumber A, Narasumber B dan Narasumber C. Berikut ini disajikan 
petikan dari hasil wawancara yang dianggap dapat menjadi masukan yang sangat strategis menentukan langkah Perpustakaan IPB ke depan.

Menghadapi era disrupsi ini Narasumber A menyatakan sebagai berikut.

".... sekarang menurut saya perpustakaan nggak boleh lepas dari pada memanfaatkan revolusi industri 4.0. Memang you like it or you don't like it, if you don't you will be disrupted. Di perpustakaan nggak bisa lagi mengandalkan prosedur konvensional yang very rigid, orang tidak bisa dikungkung oleh birokrasi yang terlalu berat, itu yang harus dikembangkan."

Pernyataan itu sesuai dengan hasil wawancara Datig (2014) kepada seorang mahasiswa internasional di New York University Abu Dhabi, "The librarian in my school library focused a lot on maintaining silence. Like, a lot. And that in turn used to make students not want to go to the library." Pustakawan yang tetap mempertahankan prinsip yang konvensional akan ditinggalkan penggunanya.

Narasumber A juga melanjutkan tentang langkah perpustakaan sekarang ini.

".... jadi kalo anda mengelola perpustakaan not only see the library, but see the surrounding object that interact with the library. .... New opportunity itu sekarang semua serba online, IoT, big data analytic, artificial intelligence. Jangan sistem perpustakaan yang konvensional saja. Perpustakaan harus keluar dari comfort rone, supaya tidak mengalami disrupted. ... Karena persaingan yang begitu ketat orang gak. bisa cuma gunakan best practice, tapi beyond best practice".

Selanjutnya disajikan salah satu keinginan Narasumber B yang menarik dan seharusnya dapat dilakukan oleh Perpustakaan IPB. Mungkin hal itu bukan sesuatu yang baru, perpustakaanperpustakaan yang kreatif dan terus mengembangkan layanannya bisa jadi sudah melakukan layanan tersebut.
"Perpustakaan perlu menginformasikan dokumen khusus, undang-undang dan peraturan yang terkait dengan bidang ilmu yang menjadi kurikulum IPB. Maksudnya di web Perpustakaan ada menu undang-undang, nanti dosen tinggal klike undang-undang perlindungan konsumen misalnya. Perpustakaan bisa cari di Google, nanti ada undang-undang agraria, undang-undang lingkungan, undang-undang pertanian, kesehatan beserta peraturannya. Perpustakaan tidak harus menyediakan filenya, tetapi dapat menyediakan link pada situs yang memiliki file dokumen tersebut."

Narasumber B juga menginginkan:

"Bagus juga kalau perpustakaan itu membuat daftar bahan pustaka dari setiap mata kuliah. Perpustakaan membuat blog untuk mata kuliah, menunjukkan buku-buku, video dari YouTube, artikelnya untuk mata kuliah tertentu. Untuk mencari tahu sumber-sumber informasi yang digunakan pada setiap mata kuliab, pustakawan dapat melakukan pendekatan kepada mahasiswa, menanyakan apa yang dibaca oleh mahasiswa. Nab itu menjadi salah satu kelebihan pustakawan, itu dia harus bisa membangun database bahan ajar yang bagus dari sumber-sumber informasi."

Berhubungan dengan kemungkinan adanya hambatan yang dihadapi mahasiswa Program Sarjana dalam melakukan penelitian dimana Perpustakaan dapat membantu, Narasumber C menyarankan sebagai berikut.

“.... Perpustakaan dapat memberikan layanan pelatiban bagaimana menulis proposal, mensitasi secara tepat, pemahaman tentang plagiarism, layanan analisis data dan interpretasi data hasil penelitian, menulis artikel ilmiab; dengan cara bersinergi atau kerjasama dengan para dosen/peneliti atau pakar di bidangnya."

Narasumber C lebih lanjut mengingatkan pustakawan IPB dalam menghadapi era industri 4.0 sebagai berikut. 
“.... kompetensi pustakawan IPB harus memiliki kompetensi dasar dalam bidang informasi dan komunikasi sesuai dengan perkembangan teknologi. Kolaborasi antara pustakawan dengan dosen penting dilakukan agar Perpustakaan dapat berperan maksimal dalam proses pembelajaran dan penelitian mahasiswa S1."

Pentingnya pustakawan menguasai teknologi informasi dan komunikasi seiring dengan perkembangan pembelajaran secara daring, Wulandari dan Nugroho (2017) juga menyarankan agar pustakawan Indonesia harus dapat mengembangkan konten elektronik sebagai sarana untuk pemenuhan kebutuhan informasi mahasiswa yang mengikuti pembelajaran online (e-learning). Untuk itu pustakawan harus memiliki keterampilan khusus terutama di bidang teknologi informasi.

Mencermati hasil wawancara dengan tiga orang dosen IPB, banyak hal yang perlu dilakukan oleh Perpustakaan IPB yang dapat dilakukan dalam jangka pendek, dengan sumber daya yang ada, maupun dalam jangka panjang yang memerlukan usaha yang khusus. Perpustakaan di era industri 4.0 harus berani berubah, harus lebih kreatif dan inovatif, membaca keinginan pengguna dengan jeli, agar tidak ditinggalkan penggunanya. Penyedia informasi saat ini bukan lagi monopoli perpustakaan, sumber-sumber informasi di internet menjadi pesaing yang luar biasa, walaupun informasinya tidak selalu benar. Menjadi tantangan bagi perpustakaan dan pustakawan menghadapi persaingan tersebut, termasuk bagi Perpustakaan IPB. Menurut Pan dkk. (2014) perpustakaan dan pustakawan perguruan tinggi mempunyai kesempatan baru membangun kembali posisinya di kampus dengan fokus pada pembelajaran mahasiswa, turut serta pada kegiatan dosen dan memaksimalkan kontribusinya pada institusi dan pendidikan tinggi secara keseluruhan.

\section{Kesimpulan}

Hasil uji korelasi antara frekuensi kunjungan mahasiswa ke Perpustakaan dan banyaknya buku Perpustakaan yang dipinjam dengan Indeks Prestasi Kumulatif (ukuran dari hasil pembelajaran) mahasiswa menunjukkan tidak ada korelasi. Manfaat Perpustakaan terhadap proses pembelajaran yang dirasakan mahasiswa Program Sarjana adalah pada koleksi jurnal elektronik, koleksi buku tercetak, fasilitas komputer dan jaringan internet di Perpustakaan, dan ruang perpustakaan yang nyaman membuat mahasiswa senang belajar di Perpustakaan. Manfaat Perpustakaan terhadap proses penelitian mahasiswa yang paling dirasakan adalah pada koleksi skripsi di repository IPB, koleksi jurnal elektronik, tersedianya komputer dan jaringan internet, dan ruangan Perpustakaan yang nyaman.

Dukungan pustakawan terhadap proses pembelajaran mahasiswa yang paling dirasakan adalah pustakawan selalu siap menjawab pertanyaan mahasiswa, membantu mahasiswa dalam mencari informasi, dan membantu mahasiswa mencari buku yang tidak ditemukan. Dalam proses penelitian dukungan pustakawan yang paling dirasakan manfaatnya adalah pustakawan membantu mahasiswa mencari informasi, memberikan saran kepada mahasiswa dalam mencari informasi yang relevan untuk penelitiannya, dan membantu mahasiswa menghindari plagiarisme pada laporan penelitiannya.

Dalam rangka meningkatkan manfaat Perpustakaan bagi mahasiswa, saran dari para narasumber antara lain Perpustakaan IPB harus mengimplementasikan konsep-konsep berbasiskan revolusi industri 4.0, tidak lagi berpegang pada prinsip yang konvensional, tetapi dapat melakukan beyond best practice; Perpustakaan membuat informasi mudah diakses oleh sivitas akademika berbasis web; Pustakawan IPB haruslah sumber 
daya manusia yang mempunyai kompetensi dasar dalam bidang informasi dan komunikasi sesuai dengan perkembangan teknologi informasi dan komunikasi.

\section{Saran}

Perpustakaan IPB perlu mempercepat implementasi berbagai layanan berbasis konsep revolusi industri 4.0, sehingga dapat mendukung mahasiswa dalam menghasilkan inovasi yang bermanfaat bagi IPB, negara dan bangsa Indonesia. Untuk itu pustakawan IPB perlu ditingkatkan keterampilan literasi informasinya, penguasaan pada teknologi informasi dan komunikasi, dan mempunyai pengetahuan yang cukup untuk terlibat lebih intensif dalam proses pembelajaran dan penelitian mahasiswa.

\section{Ucapan Terima Kasih}

Penulis sangat berterima kasih kepada Perpustakaan Nasional RI yang telah memberi kesempatan kepada penulis untuk mendapatkan dana hibah tahun 2019, sehingga kajian ini dapat dilaksanakan. Semoga kajian ini dapat bermanfaat bagi Perpustakaan dan pustakawan IPB dan juga perpustakaan dan pustakawan Indonesia.

\section{DAFTAR PUSTAKA}

Datig, I. (2014). What is a library?: International college students' perceptions of libraries. The Journal of Academic Librarianship, 40, 350-356. Diambil 2 Juli 2019 dari Science Direct database. http://dx.doi.org/10.1016/j. acalib.2014.05.001

Daruyani, S., Wilandari, Y., \& Yasin, H.

(2013). Faktor-faktor yang mempengaruhi indeks prestasi mahasiswa FSM Universitas Diponegoro semaster pertama dengan motode regresi logistik biner. Prosiding Seminar Nasional Statistika Universitas Diponegoro, 14 September 2013, 185194. Diambil 22 November 2020 dari http://eprints.undip.ac.id/40295/
Irianto, A. (2008). Statistik: Konsep dasar \& aplikasinya. Jakarta: Kencana.

Jamaluddin. (2014). Pengaruh pemanfaatan layanan perpustakaan terhadap prestasi belajar mahasiswa di Universitas Hasanuddin. JUPITER, XIII(1), 1-8. Diambil 2 Juli 2019 dari http://journal.unhas.ac.id/index.php Ljupiter/article/view/1669

Li, L.H., Wu, F., \& Su, B. (2018). Impacts of library space on learning satisfaction An empirical study of University library design in Guangzhou, China. The Journal of Academic Librarianship, 44, 724-737. Diambil 2 Juli 2019 dari Science Direct database http://doi.org/10.1016/i.acalib.2018. 10.003

Masyhuri \& Zainuddin, M. (2011). Metodologi penelitian: pendekatan praktis dan aplikatif. Ed. revisi. Bandung: Refika Aditama.

Montenegro, M., Clasing, P., Kelly, N. dkk. (2016). Library resources and students' learning outcomes: Do all the resources have the same impact on learning? The Journal of Academic Librarianship, 42, 551556. Diambil 2 Juli 2019 dari Science Direct database http://dx.doi.org/ 10.1016/j.acalib.2016.06.020

Nzivo, C.N. \& Chuanfu, C. (2013). International students' perception of library services and information resources in Chinese academic libraries. The Journal of Academic Librarianship, 39, 129-137. Diambil 2 Juli 2019 dari Science Direct database http://dx.doi.org/10.1016/j.acalib. 2012.11.004

Pan, D., Ferrer-Vinent, I.J. \& Bruehl, M. (2014). Library value in the classroom: assessing student learning outcomes from instruction and collections. The Journal of Academic Librarianship, 40, 332338. Diambil 2 Juli 2019 dari Science Direct database http://dx.doi.org/ 10.1016/i.acalib.2014. 04.011

Riduwan. (2009). Pengantar statistika sosial. Bandung: Alfabeta.

Rinto, E.E., Cogbill - Seiders, E.I. (2015). Library instruction and themed composition courses: aninvestigation of factors that impact student learning. The Journal of Academic Librarianship, 41, 
14-20. Diambil 2 Juli 2019 dari Science Direct database

http://dx.doi.org/10.1016/j.acalib.201 4.11.010

Shen, Y., Varvel, V.E. Jr. (2013). Developing data management services at the John Hopkins University. The Journal of Academic Librarianship, 39, 552-557. Diambil 2 Juli 2019 dari Science Direct database http://dx.doi.org/10.1016/ j.acalib.2013.06.002.

Sujana, J.G., Muljono, P., Lubis, D.P., Sulistyo-Basuki. (2018). The information seeking behavior of digital native and digital immigrant students of Bogor Agricultural University. Journal of Education and Learning, 12(1), 57-68.

Diambil 25 Juli 2019 dari
http://journal.uad.ac.id/index.php/Ed uLearn/ article/view/7064/pdf 218

Sujana, J.G., Siswadi, F., Isriyanti. (2019). Layanan manajemen data penelitian di Perpustakaan IPB: sebuah tantangan. Laporan Penelitian dengan dana hibah Direktorat Sumber Daya Manusia IPB. Bogor: Perpustakaan IPB.

Supranto, J. (2016). Statistik: teori dan aplikasi edisi kedelapan. Jakarta: Erlangga.

Wulandari, N.E.R., Nugroho, E. (2017). Elearning: implikasinya terhadap pelayanan perpustakaan perguruan tinggi dan peran pustakawan. Berkala Ilmu Perpustakaan dan Informasi, 13(1), 87-96. Diambil 23 Juni 2019 dari https://journal.ugm.ac.id/bip/article/ view/26199/16614 